the Western Himalayas by Sri M. K. Wali; Aspergilli by Dr. B. S. Mehrotra; humid tropics by B. S. Ahuja and K. P. Singh; sal leaf litter by Sri N. K. Jain. At the end of the symposium the following recommendations were made:

"Ecologists working on the tropical region, particularly Indian ecologists, should undertake co-operative studies to fill up the lacunæ in our knowledge as soon as possible. For achieving the purpose it is desirable to launch a vigorous and intensive programme of research with a view to obtaining data of practical and immediate applicability to agriculture, forestry and soil, water and wild life conservation. It is felt that The Forest Ecosystem Proforma prepared and pub- lished by the International Society for Tropical Ecology will be found of extensive utility. The same with a suitable amendment can be conveniently used for studies of animal and human ecology."

A committee to implement and expand the results of the symposium and to raise necessary funds needed for supporting the project in co-operation with the International Society for Tropical Ecology was formed. Further information concerning this project can be obtained from Dr. G. S. Puri, general secretary, International Society for Tropical Ecology, 10 Chatham Lines, Allahabad. The Forest Ecosystem Proforma can be obtained from the Society, price Rs. 5.

\title{
THE WEST AFRICAN RICE RESEARCH STATION
}

$\mathrm{T}$

HE West African Rice Research Station, which is situated at Rokupr in Sierra Leone, is supported by the four West African territories of Nigeria, Ghana, Sierra Leone and Gambia. It is now ten years since a free grant from the United Kingdom under the Colonial Development and Welfare Act enabled the existing experimental station of the Sierra Leone Department of Agriculture to be transformed into a major inter-territorial research station, and five years since completion of buildings and establishment enabled a full-scale research programme to be started. It is hoped that this year will mark a further stage in development and that the Station will attain the status of an independent institute.

Rice production and consumption is expanding rapidly in West Africa, not only in Sierra Leone and adjacent parts where it has long been the staple food of the population but also in all other territories where it is of more recent cultivation. Present production in the whole of West Africa is estimated to be about one and a half million tons of paddy per annum, of which just more than a quarter of a million tons is produced in Sierra Leone. In view of the important part that rice seems destined to play in the economy of West Africa as a major food crop and in efficient utilization of the land, all Governments gave support to the establishment of the Station, the basic policy of which is to carry out fundamental research on rice as a crop under West African conditions, and to advise territorial Ministries, who remain responsible for local application and extension work, on their programmes of rice development and production.

The main station at Rokupr, in addition to an area of upland for administrative, laboratory and farm buildings and staff quarters and for experimental work on upland rices, consists of a 66-acre swamp rice-farm contiguous with the estuary of the Great Scarcies River, from which it is irrigated by tidal flooding with fresh water throughout the growing season. In addition, the Station maintains small areas on other types of soil in different parts of Sierra Leone. The laboratories, which were built in 1955, are well equipped and have recently been supplemented by a series of cabinets with controlled illumination and temperature for work on growth, an opensided greenhouse for pot-work with soils and culture media, and a deep-water tank for experimental work with floating and flood-resistant rices. An airconditioned building is provided for storage of the seed of the West African varietal collection, which is maintained by the Station, the responsibilities of which also include the maintenance of nucleus pure seed stocks of established and recommended varieties for seed multiplication schemes of the contributing territories.

At present the cultivation of rice in West Africa is carried out under a wide range of notural water conditions, from those of coastal mangrove swamps to the seasonal flooding of riverain plains in the lower-rainfall areas. There are extensive and widespread areas, potentially useful for rice growing, at present undeveloped. The attention of the Station has thus been concentrated on the investigation of the rice plant in relation to its habitat and on the production of rice varieties to suit natural conditions, together with work on soils and the changes that occur in them when modification of conditions may take place during development.

Selection from local and introduced varieties of rice has given excellent results in the improvement of yields in the past, but the stage has been reached when further advances can only result from a breeding programme which includes hybridization. The primary object of the present programme is the provision of high-yielding acceptable rice varieties for all the major West African habitats, including deep-flooding areas and rain-fed uplands. While consideration is given to factors such as diseaseresistance, straw-strength and milling quality, none of these at present is of such importance as to warrant specific breeding programmes, and they are considered merely as they reflect on yield. Recent series of trials in various parts of West Africa indicate, however, that in some areas effects of light and, possibly, temperature are limiting in preventing existing established varieties from attaining their full potential, and as specific breeding programme for early maturing varieties insensitive to photoperiod is being undertaken. In conjunction, physiological investigations have been started on the effects of light and temperature on duration and yield.

Other physiological work to date has been largely designed to produce useful techniques for the plant breeders. Work on viability and dormancy has resulted in improved storage of seed and speeding up the breeding programme, while investigations into hydroponics and culture media have led to a method of clonal multiplication of considerable value in experimental use. Work on milling quality-in particular with the use of parboiling, the recommended and accepted method in West Africa-has indicated 
that modifications in established milling practice would probably increase the efficiency and output of the commercial mills to an appreciable extent.

Research on soils has been concentrated, during the past few years, on the chemistry and microbiology of mangrove soils; in particular, on the problems of their reclamation in areas where flood-waters are saline throughout the year. These soils, which are paralleled by vast areas of similar soils in many parts of the world, pose particular, problems due to their high content of sulphur and their potentiality for acid-development by microbial action on drying. Research work has now led to an understanding of the processes occurring in these soils and to the formulation of techniques of reclamation which are at present being tested in the field. More recently, attention has been paid to the changes in nutrient status of these soils-which are potentially highly fertile in their natural state--when they are reclaimed and cultivated.
Investigations are now being made into the relationship between the rice plant and soil conditions, in particular the oxidizing or reducing status of the soil and its poising by the balance of ferrous and ferric iron present. It is considered that this investigation will lead to useful techniques in the initial testing of soils for their suitability for rice growing, and for predicting the effect on them of specific modification of natural conditions.

Contributing Governments are kept informed of immediate practical recommendations, and an annual report of world-wide distribution is published to record briefly the work in progress; individual researches are reported more fully by contributions to technical journals. It is of note that within ten years of its inception the Station has been able not only to play its part in the general economic development of West Africa but also to contribute substantially to scientific knowledge of the world's major food erop. H. D. JORDAN

\section{TECHNICAL EDUCATION IN WALES}

\begin{abstract}
A RECENT report dealing with technical education in Wales* is as surprising for the boldness of its recommendations for training within industry as it is for its ambivalence about the resolution of educational and administrative problems within its purview. Within a brief sixty pages it first $\mathbf{r} \ni$ views the history of technical education in Wales with candid admissions of former shortcomings, then it surveys the great changes in industrial background. The present pattern of technical education is next reviewed, under three main headings, of courses and training for craft apprentices, student apprentices and graduate apprentices. Significant differences are noted from the rest of the British scene. In this way the report rapidly traverses the background to its terms of reference, which were "In the light of contemporary changes in the industrial pattern in Wales, to consider what educational provisions should be made to serve the best interests of industry and of those employed in it."

The fourth and final chapter of the report of the Central Advisory Council for Education (Wales) embodies the Council's observations and recommendations, some of which go well beyond the particular needs and circumstances of Wales. The report incorporates much contemporary discussion and exhortation, and thus joins in the now customary commendation of such developmonts as block-release courses, sandwich courses, pre-apprenticeship courses, group apprenticeship training schemes, a two-year Ordinary National Certificate course, the introduction of lower standard courses for now City and Guilds of London Institute examinations, and other ideas to be found in the Crowther Report and the second White Paper Better Opportunities in Technical Education.
\end{abstract}

A fundamentally new approach for industrial training in the United Kingdom is urged in the proposed establishment of a national craft apprenticeship system, especially to meet the needs of small firms which largely compose British industry, particularly in Wales. This would be administered by the State

* Ministry of Education: Central Advisory Council for Education Wales). Technical Education in Wales. Pp. ix +146 . (In English and Welsh.) (London: H.M. Stationery Office, 1961.) 78. net. through the Ministry of Education and a National Apprenticeship Council, training being given from the age of sixteen years in apprentice training centres. The centres may or may not be attached to technical colleges, and would be financed by an apprenticeship levy on industry (though curiously this important point is not mentioned in the final summary of recommendations). This proposal constitutes a strong challenge to present Government policy, and to the existing Industrial Training Council; but the report sees no other adequate way of meeting the compelling needs of the greatly increased age-groups 16-19 years coming into industry from 1963 onwards, or of meeting the needs of smaller firms.

With regard to advanced courses, the report concludes that the overall provision greatly outruns the present demand, and urges that to avoid wasteful and inefficient duplication these courses should be confined to five technical colleges-Treforest, Newport, Swansea, Wrexham, together with the Welsh College of Advanced Technology in Cardiff. The words here shown in italics illustrate the Council's refusal to grasp the essential ideas of the four-tier structure of technical education, with preferential concentration of advanced courses in the colleges of advanced technology. This is related to its somewhat despairing view of the continued existence of the Cardiff College, of which it presents a very partial picture indeed (it has 186 in sandwich courses within four years of its designation out of a total sandwich course and full-time enrolment-not mentioned-of 826 students-compared with 732 students at the University College of North Staffordshire after 10 years of existence, not to mention the former's large part-time enrolment).

The report suggests that all five colleges should be administered jointly by an administrative council which might be the technical sub-committee of the Welsh Joint Education Committee. Never was there a better example of the new Benthamism - the greatest pacification of the greatest number of local education authorities, and consequently, the strongest possible built-in deterrent to the emergence of concentrated excellence at the College of Advanced Technology. Not surprisingly, the Council concludes 